\title{
Open versus minimally invasive decompression for low-grade spondylolisthesis: analysis from the Quality Outcomes Database
}

\author{
Erica F. Bisson, MD, MPH, ${ }^{1}$ Praveen V. Mummaneni, MD, ${ }^{2}$ Michael S. Virk, MD, PhD, ${ }^{3}$ \\ John Knightly, MD, ${ }^{4}$ Mohammed Ali Alvi, MBBS, ${ }^{5}$ Anshit Goyal, MBBS, ${ }^{5}$ Andrew K. Chan, MD, ${ }^{2}$ \\ Jian Guan, MD, ${ }^{1}$ Steven Glassman, MD, ${ }^{6}$ Kevin Foley, MD, ${ }^{7}$ Jonathan R. Slotkin, MD, ${ }^{8}$ \\ Eric A. Potts, MD, ${ }^{9}$ Mark E. Shaffrey, MD, ${ }^{10}$ Christopher I. Shaffrey, MD, ${ }^{11}$ Regis W. Haid Jr., MD, ${ }^{12}$ \\ Kai-Ming Fu, MD, ${ }^{3}$ Michael Y. Wang, MD, ${ }^{13}$ Paul Park, MD, ${ }^{14}$ Anthony L. Asher, MD, ${ }^{15}$ and \\ Mohamad Bydon, MD
}

'Department of Neurological Surgery, University of Utah, Salt Lake City, Utah; ${ }^{2}$ Department of Neurological Surgery, University of California, San Francisco, California; ${ }^{3}$ Department of Neurological Surgery, Weill Cornell Medical College, New York, New York; ${ }^{4}$ Atlantic Neurosurgical Specialists, Morristown, New Jersey; ${ }^{5}$ Department of Neurologic Surgery, Mayo Clinic, Rochester, Minnesota; ${ }^{6}$ Norton Leatherman Spine Center, Louisville, Kentucky; ${ }^{7}$ Department of Neurosurgery, University of Tennessee, Memphis, Tennessee; ${ }^{8}$ Geisinger Health System, Danville, Pennsylvania; ${ }^{9}$ Goodman Campbell Brain and Spine, Indianapolis, Indiana; ${ }^{10}$ Department of Neurological Surgery, University of Virginia Health System, Charlottesville, Virginia; ${ }^{11}$ Departments of Neurological Surgery and Orthopedic Surgery, Duke University, Durham, North Carolina; ${ }^{12}$ Atlanta Brain and Spine, Atlanta, Georgia; ${ }^{3}$ Department of Neurologic Surgery, University of Miami, Florida; ${ }^{14}$ Department of Neurologic Surgery, University of Michigan, Ann Arbor, Michigan; and ${ }^{15}$ Neuroscience Institute, Carolinas Healthcare System and Carolina Neurosurgery \& Spine Associates, Charlotte, North Carolina

OBJECTIVE Lumbar decompression without arthrodesis remains a potential treatment option for cases of low-grade spondylolisthesis (i.e., Meyerding grade I). Minimally invasive surgery (MIS) techniques have recently been increasingly used because of their touted benefits including lower operating time, blood loss, and length of stay. Herein, the authors analyzed patients enrolled in a national surgical registry and compared the baseline characteristics and postoperative clinical and patient-reported outcomes (PROs) between patients undergoing open versus MIS lumbar decompression. METHODS The authors queried the Quality Outcomes Database for patients with grade I lumbar degenerative spondylolisthesis undergoing a surgical intervention between July 2014 and June 2016. Among more than 200 participating sites, the 12 with the highest enrollment of patients into the lumbar spine module came together to initiate a focused project to assess the impact of fusion on PROs in patients undergoing surgery for grade I lumbar spondylolisthesis. For the current study, only patients in this cohort from the 12 highest-enrolling sites who underwent a decompression alone were evaluated and classified as open or MIS (tubular decompression). Outcomes of interest included PROs at 2 years; perioperative outcomes such as blood loss and complications; and postoperative outcomes such as length of stay, discharge disposition, and reoperations.

RESULTS A total of 140 patients undergoing decompression were selected, of whom $71(50.7 \%)$ underwent MIS and $69(49.3 \%)$ underwent an open decompression. On univariate analysis, the authors observed no significant differences between the 2 groups in terms of PROs at 2-year follow-up, including back pain, leg pain, Oswestry Disability Index score, EQ-5D score, and patient satisfaction. On multivariable analysis, compared to MIS, open decompression was associated with higher satisfaction (OR 7.5, 95\% Cl 2.41-23.2, $\mathrm{p}=0.0005)$. Patients undergoing MIS decompression had a significantly shorter length of stay compared to the open group (0.68 days [SD 1.18] vs 1.83 days [SD 1.618], $p<0.001)$.

ABBREVIATIONS ASA = American Society of Anesthesiologists; BMI = body mass index; MIS = minimally invasive surgery; NASS = North American Spine Society; NRS = numeric rating scale; ODI = Oswestry Disability Index; $\mathrm{OL}=$ open laminectomy; $\mathrm{PRO}=$ patient-reported outcome; QOD = Quality Outcomes Database.

SUBMITTED October 16, 2019. ACCEPTED March 9, 2020.

INCLUDE WHEN CITING Published online May 8, 2020; DOI: 10.3171/2020.3.SPINE191239. 
CONCLUSIONS In this multiinstitutional prospective study, the authors found comparable PROs as well as clinical outcomes at 2 years between groups of patients undergoing open or MIS decompression for low-grade spondylolisthesis.

https://thejns.org/doi/abs/10.3171/2020.3.SPINE191239

KEYWORDS open surgery; MIS; minimally invasive surgery; decompression; spondylolisthesis; Quality Outcomes Database; QOD; spine surgery; lumbar; registry

$\mathrm{D}$ EGENERATIVE lumbar spondylolisthesis is one of the most common causes of low-back pain; the reported prevalence is $11.5 \%$ in the US according to one estimate. ${ }^{1}$ For a select group of patients in whom conservative measures have failed, a surgical intervention may be considered. ${ }^{2}$

For patients with Meyerding grade I spondylolisthesis without significant instability on lateral radiographs, decompression alone has been shown to be associated with optimum clinical outcomes. ${ }^{3-6}$ A conventional open laminectomy (OL) for spondylolisthesis involves stripping of deep paraspinal muscles away from the spinous processes and retraction to expose the lamina, and subsequently performing laminectomy with or without facetectomy to decompress the spinal canal and neural elements. However, there are some well-recognized drawbacks of this conventional technique, including tissue trauma (e.g., multifidus atrophy due to prolonged duration of retraction), disturbed arteriolar blood supply, postoperative chronic low-back pain due to altered biomechanics of the posterior column, and secondary instability. ${ }^{7-13}$ To address these concerns, minimally invasive surgery (MIS) procedures have been increasingly used to address spinal pathologies. MIS allows the surgeon to minimize trauma to normal anatomical structures while achieving optimum decompression.

Among MIS techniques, unilateral decompression performed using muscle-splitting serial tube dilators and retractors is one of the most commonly used procedures. Tubular decompression allows for effective bilateral neural decompression while protecting muscle tissue and tendon attachments, potentially causing less biomechanical instability compared to OL. ${ }^{6,14-20}$ Nevertheless, OL is still considered to be an effective procedure; it is widely performed and has been shown to have optimal long-term outcomes.

As MIS techniques are increasingly adapted, it is important to investigate their outcomes in comparison to conventional open techniques. In the current study we used a prospective national registry to compare clinical and patient-reported outcomes (PROs) between open and minimally invasive decompression among patients with grade I spondylolisthesis.

\section{Methods}

\section{Study Cohort}

For the present study, the Quality Outcomes Database (QOD) was queried for patients undergoing surgery for Meyerding grade I degenerative lumbar spondylolisthesis between July 1, 2014, and June 30, 2016. The QOD is a prospective multiinstitutional registry established in 2012 with the objective to evaluate risk-adjusted expected morbidity, 30-day clinical outcomes of interest, and 12-month PROs. The overarching goal of this registry is to establish a data-driven mechanism of providing insights into improving quality of care for routinely performed spine surgeries in the US. ${ }^{21-23}$ As of February 2019, more than 78,879 patients undergoing a lumbar surgery for degenerative disease across 105 participating sites in the nation have been enrolled in the lumbar spine surgery QOD module. ${ }^{24}$ Among these sites, the 12 with the highest enrollment of patients into the lumbar spine module came together to initiate a focused project to assess the impact of fusion on PROs in patients undergoing surgery for grade I lumbar spondylolisthesis. ${ }^{25-29}$ In order to determine the diagnosis of grade I spondylolisthesis, ${ }^{30}$ surgeons at each of the participating sites evaluated preoperative standing or dynamic radiographs. ${ }^{25-29}$ The primary outcome of interest for this study was the Oswestry Disability Index (ODI) score. Informed consent and institutional review board approval were obtained.

\section{Predictor of Interest}

For the current study, the cohort was divided into those undergoing OL and minimally invasive laminectomy. A case was considered MIS if there was use of tubular decompression. ${ }^{15}$ All patients in both groups underwent a single-level decompression.

\section{Outcomes of Interest}

The primary outcome of interest was the ODI score ${ }^{31}$ at 2-year follow-up. Secondary outcomes of interest included other PROs, such as the numeric rating scale (NRS) back pain, NRS leg pain, ${ }^{32}$ EQ-5D questionnaire, ${ }^{33}$ and North American Spine Society (NASS) satisfaction questionnaire. ${ }^{34}$ The NASS satisfaction questionnaire assesses satisfaction by using a 4-point survey with scores 1 through 4, respectively: "surgery met my expectations," "I did not improve as much as I had hoped but I would undergo the same operation for the same results," "surgery helped but I would not undergo the same operation for the same results," and "I am the same or worse as compared to before surgery." We also analyzed perioperative and postoperative clinical outcomes including operating time, blood loss, complications, postoperative length of stay, discharge disposition, and reoperations.

\section{Covariates}

The following variables were included in the analyses for the current study: ${ }^{25-29}$ 1) demographic characteristics including age, sex, body mass index (BMI), ethnicity, insurance status, education level, employment, and work- 
ers' compensation; 2) comorbidities, including smoking, diabetes, osteoporosis, coronary artery disease, anxiety, history of major depressive disorder, and American Society of Anesthesiologists (ASA) classification; 3) clinical characteristics such as symptom duration, dominant symptom, ambulation, and presence of motor deficit; and 4) baseline PROs. Other surgical variables such as intraoperative blood loss and operating time were also documented. We also compared the rate of complications between the MIS and OL groups. These complications included deep vein thrombosis, new neurological deficit, myocardial infarction, urinary tract infection, surgical site infection, hematoma, cerebrovascular accident, durotomy, and pneumonia.

\section{Statistical Analysis}

Continuous variables were summarized using the mean (SD) and compared using the t-test. Categorical variables were summarized using frequencies with proportions and compared using chi-square or Fisher's exact test. We also performed a multivariable linear regression analysis to analyze the outcomes of interest, including change in ODI, change in NRS leg and back pain, and change in EQ-5D at the 2- or 3-year follow-up. We also performed multivariable logistic regression analysis for assessing NASS patient satisfaction at the 2- or 3-year follow-up. All analyses were performed with $\mathrm{R}$ version 3.3.1 (R Foundation for Statistical Computing), using the rms and Arsenal packages. ${ }^{35}$ The $\mathrm{p}$ values were 2 -tailed and were considered significant if they were less than 0.05 .

\section{Results}

Of the 608 patients undergoing surgery for grade I spondylolisthesis across 12 sites, 140 patients (23.0\%) underwent a decompression alone. Of these, 71 patients (50.7\%) underwent an MIS decompression and 69 patients (49.3\%) underwent an open decompression.

\section{Demographic and Clinical Characteristics}

Compared to patients undergoing an open decompression, patients undergoing an MIS decompression were older (72.26 [SD 9.66] years vs 66.91 [SD 12.57] years, $\mathrm{p}=$ $0.005)$; more likely to have Medicare or Medicaid (71.8\%, $\mathrm{n}=51$ vs $47.8 \%, \mathrm{n}=33 ; \mathrm{p}=0.009)$; more likely to be unemployed $(75.7 \%, \mathrm{n}=53$ vs $54.4 \%, \mathrm{n}=37 ; \mathrm{p}=0.025)$; and more likely to have lower ASA scores $(73.2 \%, \mathrm{n}=52$ vs $55.2 \%, \mathrm{n}=37 ; \mathrm{p}=0.027$ ). We did not find any difference between the 2 groups in terms of BMI, sex, education, smoking status, diabetes, coronary artery disease, anxiety, depression, osteoporosis, dominant symptom, motor deficit, ambulation status, and symptom duration. These characteristics are presented in Table 1.

\section{Patient-Reported Outcomes}

At baseline, patients undergoing MIS or open decompression did not differ in their severity of back pain (NRS [SD] 5.592 [3.267] for MIS vs 5.446 [3.336] for open, $p=$ 0.798); leg pain (NRS [SD] 6.203 [3.003] for MIS vs 6.455 [2.840] for open, $\mathrm{p}=0.618$ ); ODI score (ODI [SD] 40.972
[18.947] for MIS vs 38.394 [17.053] for open, $p=0.405$ ); and quality of life (EQ-5D [SD] 0.578 [0.224] for MIS vs 0.608 [0.201] for open, $p=0.413$ ). Similarly, at 2 years, patients in both groups experienced significant improvement in their back pain (NRS [SD] 3.536 [2.885] for MIS vs 2.764 [2.808] for open, $\mathrm{p}=0.156$ ); leg pain (NRS [SD] 2.527 [3.096] for MIS vs 2.564 [3.131] for open, $p=0.951$ ); ODI score (ODI [SD] 23.102 [18.503] for MIS vs 22.276 [19.270] for open, $\mathrm{p}=0.813$ ); and quality of life (EQ-5D [SD] 0.799 [0.150] for MIS vs 0.764 [0.193] for open, $\mathrm{p}=$ 0.283 ). Finally, we did not observe significant differences between the 2 groups in patient satisfaction $(69.1 \%$ for MIS, $n=38$ vs $87.7 \%$ for open, $n=50 ; p=0.089$ ). These results have been summarized in Table 2 .

\section{Clinical Outcomes}

Patients undergoing MIS had an average operating time of 101.77 minutes (SD 48.47), compared to 114.21 minutes (SD 64.16) in those undergoing open decompression; the difference was not found to be significant $(\mathrm{p}=$ 0.249). Patients undergoing MIS decompression had a length of stay of 0.68 days (SD 1.18), which was significantly lower than the 1.83 days (SD 1.618) for open decompression $(p<0.001)$. Among patients undergoing MIS decompression, 93\% $(n=66)$ were discharged to home, compared to $89.6 \%(\mathrm{n}=60)$ among patients undergoing open decompression $(\mathrm{p}=0.478)$. Patients in the MIS group had a higher reoperation rate compared to those undergoing open decompression $(14.1 \%, \mathrm{n}=10$ vs $4.3 \%, \mathrm{n}=3)$; however, the difference was not statistically significant $(\mathrm{p}$ $=0.07)$. Among those undergoing reoperations $(\mathrm{n}=13)$, 6 patients had a fusion, giving an overall secondary fusion rate of $4.3 \%$; this rate was $5.6 \%(\mathrm{n}=4)$ for patients in the MIS group and $2.9 \%(\mathrm{n}=2)$ for patients in the OL group, and the difference was not found to be statistically significant $(p=0.68)$. Finally, the 2 groups did not differ in complication rate $(\mathrm{MIS}=1.4 \%, \mathrm{n}=1$ vs open $=7.2 \%$, $\mathrm{n}=5 ; \mathrm{p}=0.11)$. These results have been summarized in Table 3. Details regarding the patients who underwent a reoperation have been summarized in Tables 4 and 5. Durotomy was reported in 2 cases of OL; none of the MIS cases reported a durotomy.

\section{Multivariable Analyses}

On multivariable analyses, adjusted for an array of patient and clinical factors, open surgery compared to MIS was found to be associated with higher patient satisfaction at 2 years (OR 7.5, 95\% CI 2.41-23.2; $\mathrm{p}=0.0005)$. Type of surgery was not found to be associated with change in EQ$5 \mathrm{D}$ at 2 years, change in ODI at 2 years, change in NRS leg pain at 2 years, and change in NRS back pain at 2 years. These results have been summarized in Table 6 .

\section{Discussion}

In the current study, we found that both OL and MIS decompression are associated with significant improvement among patients undergoing surgery for low-grade spondylolisthesis, as evidenced by the decrease in back and leg pain, decrease in disability, and improvement in quality of life at 2 years (Fig. 1). 
TABLE 1. Comparison of demographic and clinical characteristics between MIS decompression and open decompression cohorts in patients with low-grade spondylolisthesis

\begin{tabular}{|c|c|c|c|c|}
\hline Characteristic & Total, N = 140 & MIS Decompression, $n=71$ & Open Decompression, $n=69$ & $\mathrm{p}$ Value \\
\hline Age in yrs & & & & 0.005 \\
\hline Mean (SD) & $69.627(11.472)$ & $72.264(9.662)$ & $66.913(12.578)$ & \\
\hline Range & $26.070-95$ & $51-95$ & $26.070-87.690$ & \\
\hline $\mathrm{BMI}$ & & & & 0.225 \\
\hline Mean (SD) & $28.735(5.380)$ & $28.190(4.688)$ & $29.297(5.993)$ & \\
\hline Range & $19.050-46.800$ & $20.250-39.870$ & $19.050-46.800$ & \\
\hline Sex & & & & 0.061 \\
\hline Female & $66(47.1 \%)$ & $39(54.9 \%)$ & $27(39.1 \%)$ & \\
\hline Male & $74(52.9 \%)$ & $32(45.1 \%)$ & $42(60.9 \%)$ & \\
\hline Insurance & & & & 0.009 \\
\hline Medicare or Medicaid & $84(60 \%)$ & $51(71.8 \%)$ & $33(47.8 \%)$ & \\
\hline Private & $55(39.3 \%)$ & $19(26.8 \%)$ & $36(52.2 \%)$ & \\
\hline VA or government & $1(0.7 \%)$ & $1(1.4 \%)$ & $0(0.0 \%)$ & \\
\hline Education & & & & 0.567 \\
\hline N-Miss & 8 & 7 & 1 & \\
\hline$<$ High school & $4(3.0 \%)$ & $1(1.6 \%)$ & $3(4.4 \%)$ & \\
\hline High school & $42(31.8 \%)$ & $20(31.2 \%)$ & $22(32.4 \%)$ & \\
\hline 2 yrs of college & $18(13.6 \%)$ & $7(10.9 \%)$ & $11(16.2 \%)$ & \\
\hline 4 yrs of college & $38(28.8 \%)$ & $22(34.4 \%)$ & $16(23.5 \%)$ & \\
\hline Postgrad college & $30(22.7 \%)$ & $14(21.9 \%)$ & $16(23.5 \%)$ & \\
\hline Employment & & & & 0.025 \\
\hline N-Miss & 2 & 1 & 1 & \\
\hline Employed \& not working & $1(0.7 \%)$ & $0(0.0 \%)$ & $1(1.5 \%)$ & \\
\hline Employed \& working & $47(34.1 \%)$ & $17(24.3 \%)$ & $30(44.1 \%)$ & \\
\hline Unemployed & $90(65.2 \%)$ & $53(75.7 \%)$ & $37(54.4 \%)$ & \\
\hline Hx of major surgery & $19(13.6 \%)$ & $8(11.3 \%)$ & $11(15.9 \%)$ & 0.419 \\
\hline Smoker & $15(10.7 \%)$ & $8(11.3 \%)$ & $7(10.1 \%)$ & 0.817 \\
\hline Diabetes & $32(22.9 \%)$ & $16(22.5 \%)$ & $16(23.2 \%)$ & 0.927 \\
\hline Coronary artery disease & $22(15.7 \%)$ & $14(19.7 \%)$ & $8(11.6 \%)$ & 0.187 \\
\hline Anxiety & $20(14.3 \%)$ & $11(15.5 \%)$ & $9(13.0 \%)$ & 0.681 \\
\hline Depression & $18(12.9 \%)$ & $10(14.1 \%)$ & $8(11.6 \%)$ & 0.660 \\
\hline Osteoporosis & $131(93.6 \%)$ & $64(90.1 \%)$ & $67(97.1 \%)$ & 0.093 \\
\hline Dominant symptom & & & & 0.164 \\
\hline Back dominant & $36(25.7 \%)$ & $20(28.2 \%)$ & $16(23.2 \%)$ & \\
\hline Back equals leg & $38(27.1 \%)$ & $15(21.1 \%)$ & $23(33.3 \%)$ & \\
\hline Leg dominant & $66(47.1 \%)$ & $36(50.7 \%)$ & $30(43.5 \%)$ & \\
\hline Motor deficit & $47(33.6 \%)$ & $26(36.6 \%)$ & $21(30.4 \%)$ & 0.442 \\
\hline Ambulation & & & & 0.448 \\
\hline Independent & $117(83.6 \%)$ & $61(85.9 \%)$ & $56(81.2 \%)$ & \\
\hline Not independent & $23(16.4 \%)$ & $10(14.1 \%)$ & $13(18.8 \%)$ & \\
\hline Symptom duration & & & & 0.214 \\
\hline$<3 \mathrm{mos}$ & $9(6.4 \%)$ & $4(5.6 \%)$ & $5(7.2 \%)$ & \\
\hline 3-12 mos & $128(91.4 \%)$ & $64(90.1 \%)$ & $64(92.8 \%)$ & \\
\hline$>12$ mos & $3(2.1 \%)$ & $3(4.2 \%)$ & $0(0.0 \%)$ & \\
\hline ASA & & & & 0.027 \\
\hline N-Miss & 2 & 0 & 2 & \\
\hline 1 or 2 & $89(64.5 \%)$ & $52(73.2 \%)$ & $37(55.2 \%)$ & \\
\hline $3-5$ & $49(35.5 \%)$ & $19(26.8 \%)$ & $30(44.8 \%)$ & \\
\hline
\end{tabular}

$\mathrm{Hx}=$ history; $\mathrm{N}$-Miss = number of patients for whom data are missing; $\mathrm{VA}=$ Veterans Affairs.

Boldface type indicates statistical significance. 
TABLE 2. Analysis of baseline, 2-year follow-up, and change in PROs between MIS decompression and open decompression cohorts

\begin{tabular}{|c|c|c|c|c|}
\hline Variable & Total, $\mathrm{N}=140$ & MIS Decompression, $n=71$ & Open Decompression, $n=69$ & p Value \\
\hline \multicolumn{5}{|l|}{ PROs at baseline } \\
\hline NRS BP & & & & 0.798 \\
\hline N-Miss & 4 & 0 & 4 & \\
\hline Mean (SD) & $5.522(3.289)$ & $5.592(3.267)$ & $5.446(3.336)$ & \\
\hline Range & 0 to 10 & 0 to 10 & 0 to 10 & \\
\hline NRS LP & & & & 0.618 \\
\hline N-Miss & 5 & 2 & 3 & \\
\hline Mean (SD) & $6.326(2.916)$ & $6.203(3.003)$ & $6.455(2.840)$ & \\
\hline Range & 0 to 10 & 0 to 10 & 0 to 10 & \\
\hline ODI & & & & 0.405 \\
\hline N-Miss & 3 & 0 & 3 & \\
\hline Mean (SD) & $39.730(18.039)$ & $40.972(18.947)$ & $38.394(17.053)$ & \\
\hline Range & 0 to 90 & 0 to 90 & 0 to 76 & \\
\hline EQ-5D & & & & 0.413 \\
\hline N-Miss & 5 & 1 & 4 & \\
\hline Mean (SD) & $0.592(0.213)$ & $0.578(0.224)$ & $0.608(0.201)$ & \\
\hline Range & 0.049 to 1 & 0.049 to 1 & 0.216 to 1 & \\
\hline \multicolumn{5}{|l|}{ PROs at 2 yrs of follow-up } \\
\hline NRS BP & & & & 0.156 \\
\hline N-Miss & 29 & 15 & 14 & \\
\hline Mean (SD) & $3.153(2.861)$ & $3.536(2.885)$ & $2.764(2.808)$ & \\
\hline Range & 0 to 10 & 0 to 10 & 0 to 10 & \\
\hline NRS LP & & & & 0.951 \\
\hline N-Miss & 30 & 16 & 14 & \\
\hline Mean (SD) & $2.545(3.100)$ & $2.527(3.096)$ & $2.564(3.131)$ & \\
\hline Range & 0 to 10 & 0 to 10 & 0 to 10 & \\
\hline ODI & & & & 0.813 \\
\hline N-Miss & 23 & 12 & 11 & \\
\hline Mean (SD) & $22.692(18.810)$ & $23.102(18.503)$ & $22.276(19.270)$ & \\
\hline Range & 0 to 78 & 0 to 78 & 0 to 64 & \\
\hline EQ-5D & & & & 0.283 \\
\hline N-Miss & 27 & 11 & 16 & \\
\hline Mean (SD) & $0.783(0.172)$ & $0.799(0.150)$ & $0.764(0.193)$ & \\
\hline Range & 0.008 to 1 & 0.378 to 1 & 0.008 to 1 & \\
\hline \multicolumn{5}{|c|}{ Change in PROs at 2 yrs of follow-up } \\
\hline Change in $\mathrm{BP}$ & & & & 0.183 \\
\hline N-Miss & 32 & 15 & 17 & \\
\hline Mean (SD) & $1.917(3.941)$ & $1.429(4.272)$ & $2.442(3.517)$ & \\
\hline Range & -10 to 10 & -10 to 10 & -4 to 10 & \\
\hline Change in LP & & & & 0.935 \\
\hline N-Miss & 34 & 18 & 16 & \\
\hline Mean (SD) & 3.632 (3.533) & 3.604 (3.543) & $3.660(3.557)$ & \\
\hline Range & -6 to 10 & -6 to 10 & -5 to 10 & \\
\hline Change in ODI & & & & 0.987 \\
\hline N-Miss & 25 & 12 & 13 & \\
\hline Mean (SD) & $15.470(19.743)$ & $15.441(20.771)$ & $15.500(18.787)$ & \\
\hline Range & -29 to 76 & -29 to 76 & -27 to 58 & \\
\hline
\end{tabular}


» CONTINUED FROM PAGE 353

TABLE 2. Analysis of baseline, 2-year follow-up, and change in PROs between MIS decompression and open decompression cohorts

\begin{tabular}{|c|c|c|c|c|}
\hline Variable & Total, N = 140 & MIS Decompression, $n=71$ & Open Decompression, $n=69$ & $p$ Value \\
\hline \multicolumn{5}{|c|}{$\begin{array}{l}\text { Change in PROs at } 2 \text { yrs of follow-up } \\
\text { (continued) }\end{array}$} \\
\hline Change in EQ-5D & & & & 0.753 \\
\hline N-Miss & 29 & 12 & 17 & \\
\hline Mean (SD) & $-0.177(0.252)$ & $-0.184(0.255)$ & $-0.169(0.250)$ & \\
\hline Range & -0.737 to 0.700 & -0.737 to 0.403 & -0.669 to 0.700 & \\
\hline Patient satisfaction at $2-3 \mathrm{yrs}^{*}$ & & & & 0.089 \\
\hline N-Miss & 28 & 16 & 12 & \\
\hline 1 & $63(56.2 \%)$ & $26(47.3 \%)$ & $37(64.9 \%)$ & \\
\hline 2 & $25(22.3 \%)$ & $12(21.8 \%)$ & $13(22.8 \%)$ & \\
\hline 3 & $11(9.8 \%)$ & $7(12.7 \%)$ & $4(7.0 \%)$ & \\
\hline 4 & $13(11.6 \%)$ & $10(18.2 \%)$ & $3(5.3 \%)$ & \\
\hline
\end{tabular}

$\mathrm{BP}=$ back pain; $\mathrm{LP}=$ leg pain.

${ }^{*}$ Measured using the NASS scoring system.

Lumbar decompression without fusion remains a potential option for cases of low-grade spondylolisthesis. ${ }^{28}$ The procedure may be preferred over fusion because of some undesirable consequences of the latter, including hardware malpositioning and failure. ${ }^{36}$ Moreover, the increasing shift toward outpatient surgery to alleviate the financial burden associated with care for patients with degenerative disease has seen a parallel increase in adoption of MIS techniques. ${ }^{37}$ The touted benefits of such techniques include less soft-tissue trauma, lower blood loss, and a shorter postoperative monitoring period. ${ }^{38}$ Innovations in MIS techniques such as the unilateral laminectomy for bilateral decompression allow effective bilateral decompression of the spine, comparable to OL. ${ }^{38}$ In the current study, we observed some of the aforementioned benefits of lumbar decompression, i.e., significantly shorter length of stay. These results are in agreement with previously published analyses, including a meta-analysis by Phan and Mobbs that showed a significantly shorter length of stay for patients undergoing an MIS decompression. ${ }^{9}$

Whereas previous studies have also shown more favorable results for MIS in terms of operating time and blood loss following the procedure, ${ }^{9}$ we found comparable results for these outcomes in our cohort. Previous studies have also shown greater improvement in PROs for patients undergoing MIS laminectomy compared to OL. ${ }^{9}$ However, we did not observe any difference in long-term ODI and EQ-5D scores between the 2 procedures. We found that patients undergoing MIS laminectomy were less likely to have long-term satisfaction with the procedure. One reason behind this finding could be that patients in the MIS group were older, and hence may have had other comorbidities and frailty, both of which have been shown to impact long-term outcomes. ${ }^{39}$ Another reason might be that

TABLE 3. Analysis of clinical outcomes between MIS decompression and open decompression cohort

\begin{tabular}{|c|c|c|c|c|}
\hline Variable & Total, N = 140 & MIS Decompression, $n=71$ & Open Decompression, $n=69$ & p Value \\
\hline Length of surgery & & & & 0.249 \\
\hline N-Miss & 23 & 19 & 4 & \\
\hline Mean (SD) & $108.68(57.8)$ & $101.77(48.47)$ & $114.21(64.16)$ & \\
\hline Length of stay & & & & $<0.001$ \\
\hline Mean (SD) & $1.243(1.521)$ & $0.676(1.180)$ & $1.826(1.618)$ & \\
\hline Discharge disposition & & & & 0.478 \\
\hline N-Miss & 2 & 0 & 2 & \\
\hline Home & $126(91.3 \%)$ & $66(93.0 \%)$ & $60(89.6 \%)$ & \\
\hline Not home & $12(8.7 \%)$ & $5(7.0 \%)$ & $7(10.4 \%)$ & \\
\hline Related return to operating room w/in 3 yrs & $13(9.3 \%)$ & $10(14.1 \%)$ & $3(4.3 \%)$ & 0.07 \\
\hline Secondary fusion rate & $6(4.3 \%)$ & $4(5.6 \%)$ & $2(2.9 \%)$ & 0.68 \\
\hline Complication rate & $6(4.3 \%)$ & $1(1.4 \%)$ & $5(7.2 \%)$ & 0.11 \\
\hline
\end{tabular}

Boldface type indicates statistical significance. 
TABLE 4. Reoperation details

\begin{tabular}{|c|c|c|c|c|c|c|}
\hline Group & Index Procedure & $\begin{array}{l}\text { Index } \\
\text { Procedure } \\
\text { Laterality }\end{array}$ & Reason for Reop & Reop Procedure & $\begin{array}{l}\text { Revision } \\
\text { Fusion }\end{array}$ & $\begin{array}{l}\text { Duration Btwn } \\
\text { Index \& Revision } \\
\text { Surgery }\end{array}$ \\
\hline \multicolumn{7}{|l|}{ MIS } \\
\hline MIS_1 & $\begin{array}{l}\text { L4-5 decompressive partial } \\
\text { rt hemilaminectomy, nerve } \\
\text { root decompression, } \\
\text { through midline incision }\end{array}$ & Unilat & $\begin{array}{l}\text { New It-sided (contralat to } \\
\text { index) LP }\end{array}$ & $\begin{array}{l}\text { MIS L4-5 midline incision, It } \\
\text { hemilaminectomy }\end{array}$ & No & $18 \mathrm{mos}$ \\
\hline MIS_2 & L4-5 It hemilaminectomy & Unilat & Re-emergence of symptoms & L3-5 OL \& microdiscectomy & No & $9 \mathrm{mos}$ \\
\hline MIS_3 & L3-4 rt laminectomy & Unilat & $\begin{array}{l}\text { Recurrence of rt-sided pain, } \\
\text { MRI revealed L2-5 stenosis }\end{array}$ & L2-5 OL \& foraminotomy & No & $7 \mathrm{mos}$ \\
\hline MIS_4 & $\begin{array}{l}\text { L4-5 partial rt hemilaminecto- } \\
\text { my, along w/ a microscopic } \\
\text { nerve root decompression }\end{array}$ & Unilat & $\begin{array}{l}\text { Persistent LP, MRI revealed } \\
\text { persistent foraminal steno- } \\
\text { sis at L4-5 }\end{array}$ & Details unknown & Yes & $2 \mathrm{yrs}$ \\
\hline MIS_5 & $\begin{array}{l}\text { Rt L5-S1 decompression w/ } \\
\text { iO-Flex device }\end{array}$ & Unilat & $\begin{array}{l}\text { Persistent symptoms, MRI } \\
\text { showed swelling of rt L5 } \\
\text { nerve root }\end{array}$ & $\begin{array}{l}\text { MIS L5-S1 decompression } \\
\quad \text { \& TLIF }\end{array}$ & Yes & 3 mos \\
\hline MIS_6 & $\begin{array}{l}\text { L4-5 bilat hemilaminectomy, } \\
\text { medial facetectomies, } \\
\text { foraminotomies }\end{array}$ & Bilat & $\begin{array}{l}\text { Recurrent bilat hip pain, imag- } \\
\text { ing revealed L4-5 synovial } \\
\text { cyst }\end{array}$ & $\begin{array}{l}\text { Open L4-5 bilat partial } \\
\text { laminectomies, medial } \\
\text { facetectomies, forami- } \\
\text { notomies }\end{array}$ & No & $1 \mathrm{yr}$ \\
\hline MIS_7 & $\begin{array}{l}\text { L4/5 microdiscectomy w/ a } \\
\text { Taylor retractor }\end{array}$ & Bilat & Persistent foot drop & L4/5 \& L5/S1 MIS TLIF & Yes & $1 \mathrm{yr}$ \\
\hline MIS_8 & $\begin{array}{l}\text { L5/S1 foraminotomy w/ a } \\
\text { Taylor retractor }\end{array}$ & Unilat & $\begin{array}{l}\text { Unrelated to index procedure; } \\
\text { new disc herniation }\end{array}$ & $\begin{array}{l}\text { L3/4 \& L4/5 endoscopic disc- } \\
\text { ectomy }\end{array}$ & No & 2 yrs \\
\hline MIS_9.1 & $\begin{array}{l}\text { L4-5 bilat partial hemilaminot- } \\
\text { omy, exploration, decom- } \\
\text { pression \& foraminotomy, rt } \\
\text { microdiscectomy }\end{array}$ & Bilat & $\begin{array}{l}\text { Recurrent herniation } L 4-5 \text {, } \\
\text { re-emergence of symptoms } \\
4 \text { wks postop }\end{array}$ & $\begin{array}{l}\text { L4-5 rt microsurgical } \\
\text { re-exploration, lysis of } \\
\text { adhesions, discectomy }\end{array}$ & No & 2 mos \\
\hline MIS_9.2 & & & $\begin{array}{l}\text { Persistently symptomatic after } \\
\text { 1st reop }\end{array}$ & $\begin{array}{l}\text { L4-5 transfacet lumbar } \\
\text { interbody fusion }\end{array}$ & Yes & $\begin{array}{l}3 \text { mos after } \\
\text { reop, } 5 \text { mos } \\
\text { after index op }\end{array}$ \\
\hline MIS_10 & $\begin{array}{l}\text { L5-S1 MIS bilat decompres- } \\
\text { sion via unilat It tubular } \\
\text { approach }\end{array}$ & Bilat & $\begin{array}{l}\text { Re-emergence of symptoms, } \\
\text { new It LP \& weakness, L5- } \\
\text { S1 disc collapse, spondylo- } \\
\text { listhesis }\end{array}$ & $\begin{array}{l}\text { L5-S1 It hemilaminotomy, } \\
\text { medial facetectomy, fo- } \\
\text { raminotomy w/ microdisc- } \\
\text { ectomy }\end{array}$ & No & 2 mos \\
\hline \multicolumn{7}{|l|}{ Open } \\
\hline Open_1 & $\begin{array}{l}\text { L4-5 It laminotomies, mesial } \\
\text { facetectomy }\end{array}$ & Unilat & $\begin{array}{l}\text { Contralat pain (rt side) at } \\
\text { follow-up. MRI: L4-5 w/ } \\
\text { grade I anterior listhesis of } \\
\text { L4 on L5, worse in flexion. } \\
\text { Bilat synovial cyst at L4-5, } \\
\text { L5-S1 degenerative facet } \\
\text { arthropathy }\end{array}$ & L4-5 \& L5-S1 PLIF & Yes & $7 \mathrm{mos}$ \\
\hline Open_2 & L1-2 OL & Bilat & $\begin{array}{l}\text { Recurrent herniation, synovial } \\
\text { cyst leading to central ste- } \\
\text { nosis; sudden onset of hip } \\
\text { pain \& LP }\end{array}$ & L1-2 OL, same side & No & 3 mos \\
\hline Open_3 & L3-4 OL, bilat & Bilat & $\begin{array}{l}\text { Symptoms resolved for ap- } \\
\text { prox } 2 \text { mos, then patient } \\
\text { developed new radicular } \\
\text { symptoms at L5 \& S1 }\end{array}$ & $\begin{array}{l}\text { Lt L3 hemilaminectomy \& } \\
\text { L3/4 foraminotomy, L4-5 } \\
\text { TLIF }\end{array}$ & Yes & $8 \mathrm{mos}$ \\
\hline
\end{tabular}

Approx = approximately; PLIF = posterior lumbar interbody fusion; TLIF = transforaminal lumbar interbody fusion . 
TABLE 5. PROs for patients undergoing a reoperation

\begin{tabular}{ccrccc}
\hline Group & Follow-Up Time & ODI & EQ-5D & NRS & Patient Satisfaction \\
\hline MIS & & & & & \\
\hline MIS_1 & 2 yrs after reop & 0 & 0.827 & Back: 3, leg: 0 & 1 \\
\hline MIS_2 & 1 yr after reop & 25 & 0.778 & Back: 7, leg: 7 & 1 \\
\hline MIS_3 & 3 yrs after reop & 18 & 0.778 & Back: 5, leg: 3 & 1 \\
\hline MIS_4 & 1 yr after reop (performed elsewhere) & 0 & 1 & Back: 0, leg: 0 & 4 \\
\hline MIS_5 & 3 yrs after reop & 53 & 0.708 & Back: 5, leg: 0 & 2 \\
\hline MIS_6 & 2 yrs after reop & 3 & 0.810 & Back: 2, leg: 4 & 2 \\
\hline MIS_7 & NA & NA & NA & NA & NA \\
\hline MIS_8 & NA & NA & NA & NA & NA \\
\hline MIS_9 & 1 yr after last reop & 31 & 0.312 & Back: 0, leg: 0 & 1 \\
\hline MIS_10 & 2 yrs after reop & & & & 4 \\
\hline Open & & 7 & 1 & Back: 1, leg: 0 & 1 \\
\hline Open_1 & 2 yrs after reop & 29 & 0.308 & Back: 8, leg: 0 & 1 \\
\hline Open_2 & 2 yrs after reop & 20 & 0.761 & Back: 4, leg: 4 & 2 \\
\hline Open_3 & 1 yr after reop & & & Back: 8, leg: 0 \\
\hline
\end{tabular}

$\mathrm{NA}=$ not applicable.

TABLE 6. Significant predictors in multivariable analyses for outcomes of interest

\begin{tabular}{|c|c|c|c|}
\hline Variable & $\begin{array}{l}\text { Adjusted } \beta \\
\text { Coefficient }\end{array}$ & $95 \% \mathrm{Cl}$ & $p$ Value \\
\hline \multicolumn{4}{|l|}{ Change in EQ-5D } \\
\hline Baseline EQ-5D & 0.38 & 0.30 to 0.47 & $<0.001$ \\
\hline \multicolumn{4}{|l|}{ Change in ODI } \\
\hline Diabetes & -8.5 & -16.82 to -0.30802 & 0.04 \\
\hline Baseline NRS BP & 0.69 & -11.72 to -0.55 & 0.03 \\
\hline Baseline ODI & 19.31 & 13.77 to 24.84 & $<0.001$ \\
\hline \multicolumn{4}{|l|}{ Change in NRS LP } \\
\hline Baseline NRS LP & 2.16 & 1.24 to 3.09 & $<0.001$ \\
\hline \multicolumn{4}{|l|}{ Change in NRS BP } \\
\hline $\begin{array}{l}\text { Unemployed vs } \\
\text { employed }\end{array}$ & 2.06 & 0.54 to 3.6 & 0.0085 \\
\hline Baseline NRS BP & & & $<0.001$ \\
\hline Variable & $\begin{array}{l}\text { Adjusted } \\
\text { OR }\end{array}$ & $95 \% \mathrm{Cl}$ & p Value \\
\hline \multicolumn{4}{|l|}{ Patient satisfaction } \\
\hline $\begin{array}{l}\text { Employment: employed } \\
\& \text { not working vs } \\
\text { unemployed }\end{array}$ & 0.003 & 0.00002 to 0.004 & 0.001 \\
\hline $\begin{array}{l}\text { Dominant symptom: BP } \\
=\mathrm{LP} \text { vs leg dominant }\end{array}$ & 0.12 & 0.03 to 0.4 & 0.003 \\
\hline $\begin{array}{l}\text { OL vs MIS } \\
\text { laminectomy }\end{array}$ & 7.5 & 2.41 to 23.2 & 0.0005 \\
\hline
\end{tabular}

All models adjusted for age, BMI, sex, insurance status, employment status at baseline, smoking status, diabetes, depression, predominant symptom, presence of motor deficit, ambulation status at presentation, symptom duration, ASA grade, NRS back pain at baseline, NRS leg pain at baseline, ODI at baseline, and EQ-5D at baseline. patients in the MIS group were more likely to be receiving Medicare and Medicaid compared to patients in the OL group, who were more likely to have private insurance; insurance status has been shown to have an impact on patient-reported metrics. Nevertheless, one possible reason behind a lower satisfaction rate in the MIS may be attributed to inadequate decompression achieved, particularly in cases in which there was bilateral compression. The higher reoperation rate observed in our results may also be attributed to inadequate decompression. Previous studies have also shown a lower secondary fusion rate following MIS decompression. ${ }^{6}$ However, in our cohort the secondary fusion rate was found to be comparable between the 2 groups $(5.6 \%$ vs $2.9 \%, \mathrm{p}=0.68)$.

\section{Limitations of the Study}

The present study may have some limitations. First, this study was a nonrandomized evaluation of several practices without standardization of surgical decision-making. Hence, there may be heterogeneity in the patient selection process, rendering the study susceptible to selection bias. Second, the current study was not powered to detect differences in the outcomes observed here. Third, analyses to evaluate cost-effectiveness were not performed, which have previously been shown to favor the MIS procedure. ${ }^{40}$ Moreover, information regarding the specific approach (i.e., unilateral vs bilateral decompression) was not documented. Finally, postoperative radiographic outcomes including sagittal motion and difference in slip percentage at follow-up were not reported, which may have further strengthened our results.

\section{Conclusions}

These results indicate that lumbar decompression without fusion remains an effective procedure to address low-grade spondylolisthesis. We found comparable results 

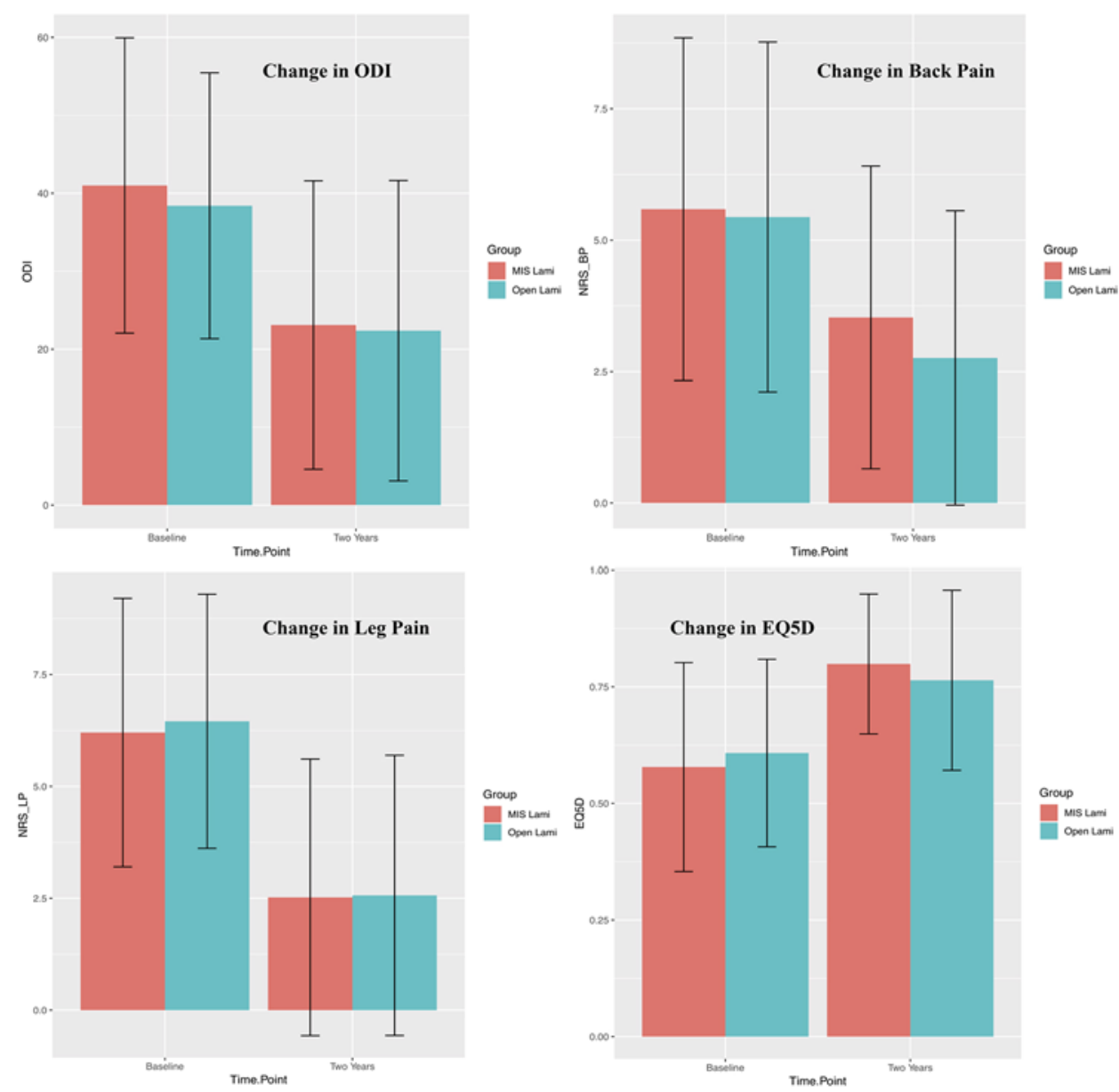

FIG. 1. Bar graphs showing PROs at baseline and at 2 years for MIS and open decompression. Whiskers represent the IQR. BP = back pain; Lami = laminectomy; LP = leg pain. Figure is available in color online only.

between OL and MIS techniques. Ultimately, decisionmaking for open versus MIS decompression may depend on surgeon preference.

\section{References}

1. Ko S-B, Lee S-W. Prevalence of spondylolysis and its relationship with low back pain in selected population. Clin Orthop Surg. 2011;3(1):34-38.

2. Weinstein JN, Lurie JD, Tosteson TD, et al. Surgical versus nonsurgical treatment for lumbar degenerative spondylolisthesis. N Engl J Med. 2007;356(22):2257-2270.

3. Eismont FJ, Norton RP, Hirsch BP. Surgical management of lumbar degenerative spondylolisthesis. J Am Acad Orthop Surg. 2014;22(4):203-213.

4. Kristof RA, Aliashkevich AF, Schuster M, et al. Degenerative lumbar spondylolisthesis-induced radicular compression: nonfusion-related decompression in selected patients without hypermobility on flexion-extension radiographs. J Neurosurg. 2002;97(3)(suppl):281-286.

5. Mulholland RC. Degenerative lumbar spondylolisthesis: a meta-analysis of literature 1970-1993. Spine (Phila Pa 1976). 1995;20(17):1957-1958.

6. Schöller K, Alimi M, Cong GT, Christos P, Hartl R. Lumbar spinal stenosis associated with degenerative lumbar spondylolisthesis: a systematic review and meta-analysis of secondary fusion rates following open vs minimally invasive decompression. Neurosurgery. 2017;80(3):355-367.

7. Airaksinen O, Herno A, Kaukanen E, et al. Density of lumbar muscles 4 years after decompressive spinal surgery. Eur Spine J. 1996;5(3):193-197.

8. Mobbs RJ, Sivabalan P, Li J. Minimally invasive surgery compared to open spinal fusion for the treatment of degenerative lumbar spine pathologies. J Clin Neurosci. 2012;19(6):829-835.

9. Phan K, Mobbs RJ. Minimally invasive versus open laminectomy for lumbar stenosis: a systematic review and metaanalysis. Spine (Phila Pa 1976). 2016;41(2):E91-E100.

10. Postacchini F, Cinotti G, Perugia D, Gumina S. The surgical treatment of central lumbar stenosis. Multiple laminotomy compared with total laminectomy. J Bone Joint Surg Br. 1993;75(3):386-392.

11. Radcliff K, Curry P, Hilibrand A, et al. Risk for adjacent segment and same segment reoperation after surgery for lumbar stenosis: a subgroup analysis of the Spine Patient Outcomes Research Trial (SPORT). Spine (Phila Pa 1976). 2013;38(7):531-539.

12. Thomé $\mathrm{C}$, Zevgaridis $\mathrm{D}$, Leheta $\mathrm{O}$, et al. Outcome after less-invasive decompression of lumbar spinal stenosis: a randomized comparison of unilateral laminotomy, bilateral laminotomy, and laminectomy. J Neurosurg Spine. 2005;3(2):129-141.

13. Usman M, Ali M, Khanzada K, et al. Unilateral approach 
for bilateral decompression of lumbar spinal stenosis: a minimal invasive surgery. J Coll Physicians Surg Pak. 2013;23(12):852-856.

14. Bresnahan L, Ogden AT, Natarajan RN, Fessler RG. A biomechanical evaluation of graded posterior element removal for treatment of lumbar stenosis: comparison of a minimally invasive approach with two standard laminectomy techniques. Spine (Phila Pa 1976). 2009;34(1):17-23.

15. Chan AK, Bisson EF, Bydon M, et al. A comparison of minimally invasive transforaminal lumbar interbody fusion and decompression alone for degenerative lumbar spondylolisthesis. Neurosurg Focus. 2019;46(5):E13.

16. Perez-Cruet MJ, Foley KT, Isaacs RE, et al. Microendoscopic lumbar discectomy: technical note. Neurosurgery. 2002;51(5) (suppl):S129-S136.

17. Rosen DS, O’Toole JE, Eichholz KM, et al. Minimally invasive lumbar spinal decompression in the elderly: outcomes of 50 patients aged 75 years and older. Neurosurgery. 2007;60(3):503-510.

18. Smith MM, Foley KT. Microendoscopic discectomy: surgical technique and initial clinical results. Clin Neurol Neurosurg. 1997;99(S1):S105.

19. Smith ZA, Vastardis GA, Carandang G, et al. Biomechanical effects of a unilateral approach to minimally invasive lumbar decompression. PLoS One. 2014;9(3):e92611.

20. Tomasino A, Parikh K, Steinberger J, et al. Tubular microsurgery for lumbar discectomies and laminectomies in obese patients: operative results and outcome. Spine (Phila Pa 1976). 2009;34(18):E664-E672.

21. Devin CJ, Bydon M, Alvi MA, et al. A predictive model and nomogram for predicting return to work at 3 months after cervical spine surgery: an analysis from the Quality Outcomes Database. Neurosurg Focus. 2018;45(5):E9.

22. Kerezoudis P, Devin CJ, Goncalves S, et al. The role of clinical registries in health care. In: Guillaume DJ, Hunt MA, eds. Quality and Safety in Neurosurgery. Academic Press; 2018:53-67.

23. McGirt MJ, Speroff T, Dittus RS, et al. The National Neurosurgery Quality and Outcomes Database (N²QOD): general overview and pilot-year project description. Neurosurg Focus. 2013;34(1):E6.

24. NeuroPoint Alliance. QOD spine registries. Accessed March 16, 2020. https://www.neuropoint.org/registries/qod-spine/

25. Asher AL, Kerezoudis P, Mummaneni PV, et al. Defining the minimum clinically important difference for grade I degenerative lumbar spondylolisthesis: insights from the Quality Outcomes Database. Neurosurg Focus. 2018;44(1):E2.

26. Chan AK, Bisson EF, Bydon M, et al. Obese patients benefit, but do not fare as well as nonobese patients, following lumbar spondylolisthesis surgery: an analysis of the Quality Outcomes Database. Neurosurgery. 2020;86(1):80-87.

27. Chan AK, Bisson EF, Bydon M, et al. Women fare best following surgery for degenerative lumbar spondylolisthesis: a comparison of the most and least satisfied patients utilizing data from the Quality Outcomes Database. Neurosurg Focus. 2018;44(1):E3.

28. Chan AK. Erratum. Laminectomy alone versus fusion for grade 1 lumbar spondylolisthesis in 426 patients from the prospective Quality Outcomes Database. J Neurosurg Spine. 2019;30(6):858-859.

29. Mummaneni PV, Bisson EF, Kerezoudis P, et al. Minimally invasive versus open fusion for Grade I degenerative lumbar spondylolisthesis: analysis of the Quality Outcomes Database. Neurosurg Focus. 2017;43(2):E11.

30. Meyerding HW. Diagnosis and roentgenologic evidence in spondylolisthesis. Radiology. 1933;20(2):108-120.

31. Fairbank JC, Pynsent PB. The Oswestry Disability Index. Spine (Phila Pa 1976). 2000;25(22):2940-2952.
32. Langley GB, Sheppeard H. The visual analogue scale: its use in pain measurement. Rheumatol Int. 1985;5(4):145-148.

33. EuroQol Group. EuroQol-a new facility for the measurement of health-related quality of life. Health Policy. 1990;16(3):199-208

34. Daltroy LH, Cats-Baril WL, Katz JN, et al. The North American Spine Society lumbar spine outcome assessment instrument: reliability and validity tests. Spine (Phila Pa 1976). 1996;21(6):741-749.

35. An Arsenal of " $R$ " functions for large-scale statistical summaries [R package arsenal version 2.0.0]. Accessed March 16, 2020. https://cran.r-project.org/web/packages/ arsenal/index.html

36. Alpert HW, Farley FA, Caird MS, et al. Outcomes following removal of instrumentation after posterior spinal fusion. $J$ Pediatr Orthop. 2014;34(6):613-617.

37. Basil GW, Wang MY. Trends in outpatient minimally invasive spine surgery. J Spine Surg. 2019;5(suppl 1):S108S114.

38. Ha S, Hong Y, Lee S. Minimally invasive lumbar spinal decompression in elderly patients with magnetic resonance imaging morphological analysis. Asian Spine $J$. 2018;12(2):285-293.

39. Moskven E, Bourassa-Moreau É, Charest-Morin R, et al. The impact of frailty and sarcopenia on postoperative outcomes in adult spine surgery. A systematic review of the literature. Spine J. 2018;18(12):2354-2369.

40. Johans SJ, Amin BY, Mummaneni PV. Minimally invasive lumbar decompression for lumbar stenosis: review of clinical outcomes and cost effectiveness. J Neurosurg Sci. 2015;59(1):37-45.

\section{Disclosures}

Dr. Bisson is a consultant for Stryker, nView, and MiRus. She has direct stock ownership in MiRus. Dr. Chan receives support from Orthofix, Inc., for a non-study-related clinical or research effort that he oversees. Dr. Foley is a consultant for Medtronic. He has direct stock ownership in Digital Surgery Systems, Discgenics, DuraStat, LaunchPad Medical, Medtronic, NuVasive, Practical Navigation/Fusion Robotics, SpineWave, TDi, and Triad Life Sciences. He holds patents with Medtronic and NuVasive, and he receives royalties from Medtronic. He is on the boards of directors of Digital Surgery Systems, Discgenics, DuraStat, LaunchPad Medical, Practical Navigation/Fusion Robotics, TDi, and Triad Life Sciences. Dr. Fu is a consultant for SI Bone, Globus, and Johnson \& Johnson. Dr. Glassman is a consultant for Medtronic and $\mathrm{K} 2 \mathrm{M} / \mathrm{Stryker}$. He receives royalties from and is a patent holder with Medtronic. He received clinical or research support for the study described (includes equipment and material) from Intellirod Spine, Inc., Pfizer, Cerapedics, Inc., the Scoliosis Research Society, and Medtronic. He is an employee of Norton Healthcare. He is chair of the American Spine Registry and past president of the Scoliosis Research Society. Dr. Haid receives royalties from Globus Medical, Medtronic, and NuVasive. He is a shareholder in Globus Medical, NuVasive, Paradigm Spine, SpineWave, and VerticalHealth (SpineUniverse). Dr. Knightly is the chairperson of NeuroPoint Alliance. Dr. Mummaneni is a consultant for DePuy Synthes, Globus, and Stryker. He has direct stock ownership in Spinicity/ISD. He received clinical or research support for the study described (includes equipment and material) from NREF. He receives support from AOSpine for a non-study-related clinical or research effort that he oversees. He receives royalties from Thieme Publishers, Springer Publishers, and DePuy Synthes. Dr. Park is a consultant for Globus Medical and NuVasive, and he receives royalties from Globus Medical. He receives support from DePuy for a non-study-related clinical or research effort that he oversees. Dr. Potts is a patent holder with and a consultant for Medtronic. Dr. C. I. Shaffrey is a 
consultant for NuVasive, Medtronic, SI Bone, and Siemens. He has direct stock ownership in NuVasive and Zimmer Biomet, and he is a patent holder with NuVasive and Medtronic. Dr. Virk is a consultant for DePuy Synthes, Globus Medical, and BrainLab, Inc. Dr. Wang is a consultant for DePuy Synthes Spine, Stryker, and Spineology. He is a patent holder with DePuy Synthes Spine, and he has direct stock ownership in ISD and Medical Device Partners.

\section{Author Contributions}

Acquisition of data: Alvi, Goyal. Analysis and interpretation of data: Bisson, Mummaneni, Alvi, Goyal, Chan. Drafting the article: Bisson, Mummaneni, Alvi, Goyal, Chan. Critically revising the article: Bydon, Bisson, Mummaneni, Knightly, Alvi,
Chan. Reviewed submitted version of manuscript: Bydon, Bisson, Mummaneni, Virk, Knightly, Chan, Guan, Glassman, Foley,

Slotkin, Potts, ME Shaffrey, CI Shaffrey, Haid, Fu, Wang, Park, Asher. Approved the final version of the manuscript on behalf of all authors: Bydon. Statistical analysis: Alvi. Administrative/ technical/material support: Bydon, Bisson, Mummaneni, Virk, Knightly. Study supervision: Bydon, Bisson, Mummaneni, Knightly.

\section{Correspondence}

Mohamad Bydon: Mayo Clinic, Rochester, MN. bydon. mohamad@mayo.edu. 